Tropical Journal of Pharmaceutical Research October 2017; 16 (10): 2487-2500

ISSN: $1596-5996$ (print); 1596-9827 (electronic)

(C) Pharmacotherapy Group, Faculty of Pharmacy, University of Benin, Benin City, 300001 Nigeria.

All rights reserved.

Available online at http://www.tjpr.org

Original Research Article

http://dx.doi.org/10.4314/tjpr.v16i10.24

\title{
Spectrophotometric and theoretical studies on the determination of etilefrine hydrochloride in pharmaceutical formulations and biological samples
}

\author{
Ahmed Mohamed El Defrawy ${ }^{1,2}$ and Amr Lotfy Saber ${ }^{2,3 *}$ \\ ${ }^{1}$ Department of Chemistry, Faculty of Science, Mansoura University, Mansoura, Egypt, ${ }^{2}$ Department of Chemistry, Faculty of \\ Applied Science, Umm al-Qura University, Makkah, Saudi Arabia, ${ }^{3}$ Department of Chemistry, Faculty of Science, Zagazig \\ University, Zagazig, Egypt
}

*For correspondence: Email: alshefny@yahoo.com

Sent for review: 15 March 2017

Revised accepted: 9 September 2017

\begin{abstract}
Purpose: To develop a simple and cost effective spectrophotometric method for the determination of etilefrine hydrochloride (ET) in pharmaceutical formulations and human plasma.

Methods: The method is based on extraction of ET into chloroform as ion-pair complexes with bromocresol green (BCG) and methyl orange (MO) in acidic medium. The interaction of ET with BCG and $M O$ reagents were investigated using $B 3 L Y P / 6-31 G(d)$ level of theory. The geometrical parameters of the interacting species and the ion pairs formed were characterized based on their frontier molecular orbitals, atomic charges, electrostatic potential map, as well as NBO analysis.

Results: The colored species exhibited absorption maxima at 410 and $479 \mathrm{~nm}$ for the two systems in universal buffer of $\mathrm{pH}$ range (3.0 - 3.5), with molar absorptivity of $2.4 \times 10^{4}$ and $1.7 \times 10^{4} \mathrm{Lmol}^{1} \mathrm{~cm}^{-1}$, for $B C G$ and MO methods, respectively. The methods demonstrated good linearity with correlation coefficient ranging from $0.9987-0.9991$ in the concentration ranges $0.5-16$ and $2.0-18 \mu \mathrm{gmL}^{-1}$ for $B C G$ and $M O$ methods, respectively. The composition ratio of the ion-association complexes was 1:1 in all cases as established by Job's method. Sandell,s sensitivity, correlation coefficient, detection and quantification limits were also calculated. Molecular descriptors were obtained based on optimized structures of the molecules under investigation, by applying the B3LYP/6-31G(d) method, and used to interpret the mode of interaction between these molecules to form the investigated ion pairs.

Conclusion: The proposed methods make use of simple reagents, which a basic analytical laboratory can afford. No interference was observed from common pharmaceutical excipients and additives. ETMO ion pair has a larger interaction energy (higher stability) than ET-BCG ion pair as inferred from their interaction energies.
\end{abstract}

Keywords: Density functional theory, Etilefrine hydrochloride, Ion pair complex, Spectrophotometry, Bromocresol green, Methyl orange, Geometric analysis

Tropical Journal of Pharmaceutical Research is indexed by Science Citation Index (SciSearch), Scopus, International Pharmaceutical Abstract, Chemical Abstracts, Embase, Index Copernicus, EBSCO, African Index Medicus, JournalSeek, Journal Citation Reports/Science Edition, Directory of Open Access Journals (DOAJ), African Journal Online, Bioline International, Open-J-Gate and Pharmacy Abstracts

\section{INTRODUCTION}

Etilefrine hydrochloride, 2-ethylamino-I-(3hydroxyphenyl) ethanol hydrochloride, is an amine that is known with its sympathomimetic activity has been utilized for a long time as a part of the treatment of orthostatic issue [1]. It shows a significant first-pass metabolic process going through the gut wall and found to show interindividual variety in bioavailability [2]. It is utilized as anti-hypotensive medication, in the counteractive action of vasovagal syncope, and in the prohibition of sickle cell infection induced priapism [3,4]. 
Etilefrine has been detected by a couple of systematic techniques including spectrophotometry [5], differential derivative spectrophotometry [6], flow injection chemiluminescence [7], potentiometry [8] in addition to ${ }^{1}$ HNMR spectroscopy [9]. Gas chromatography with mass spectrometry $[10,11]$ in addition to fluid scintillation counting of the radioactively labeled drug technique [12], have been the primary strategies used to detect etilefrine in plasma and urine in pharmacokinetic studies. The high performance liquid chromatographic (HPLC) strategies are precise and specific. Nowadays, HPLC combined with electrochemical location has been generally utilized for the determination of drug compound in biological samples, as a result of its improved selectivity and affectability $[13,14]$. A systematic approach must be undertaken and knowledge on the reactivity and stability of interacting system is essential in order to help in the explanation of the experimental findings. Recently, DFT as quantum chemical calculation provides an alternative to achieve this objective [14-18]. Instead, only the structure of the species involved is required as an input to the calculation. In this work, the interactions of ET with BCG and $\mathrm{MO}$ were investigated based on quantum chemical calculations. This was done by determining the HOMO/LUMO energy values and energy gap, global reactivity indexes, interaction energies, atomic charges of the species and its ion pairs in addition to NBO analysis.

The aim of the present work was to develop a simple, reliable and accurate extractive spectrophotometric method for the determination of $E T$ in pure form and in the pharmaceutical preparations available in Egyptian markets. In addition to that, the mode of interaction between the molecules forming the ion pair by theoretical studies.

\section{EXPERIMENTAL}

\section{Reagents and solutions}

Etilefrine hydrochloride was kindly donated by pharma company, El-Obour City Egypt. All of the chemicals used were of analytical or pharmaceuticalgrade and all solutions were prepared in doubly distilled water without further purification. Dissolving $10 \mathrm{mg}$ of pure drug in a few drops of ethanol then transferring it into a $100 \mathrm{~mL}$ measuring flask, and diluting it with distilled water up to the marking for preparation a stock solution of ET $\left(100 \mu \mathrm{g} \mathrm{mL}^{-1}\right)$.

\section{Apparatus}

Spectrophotometric measurements had been done using a UV-visible spectrophotometer model JASCO530 UV-Vis with quartz cells (path length $10 \mathrm{~mm}$ ). The $\mathrm{pH}$-meter, model $\mathrm{HI} 8014$, HANNA Instruments (Italy) were used to measure $\mathrm{pH}$ values.

\section{Procedure for calibration curve}

Aliquots of $(E T)$ were transferred into a 10 series of $50 \mathrm{~mL}$ separating funnels as the concentration range stated in Table 1. A $1.0 \mathrm{~mL}$ of dye solution $\left(1.0 \times 10^{-3} \mathrm{M}\right)$ and $5.0 \mathrm{~mL}$ of buffer solutions of $(\mathrm{pH} 2$ - 10) were added then completed the volume of the aqueous phase to $10 \mathrm{~mL}$ with distilled water and then shaking vigorously was done for $2 \mathrm{~min}$, after added $10 \mathrm{~mL}$ of chloroform to funnels. For clear separation, the two phases should be allowed to stand and the organiclayer was dried using anhydrous sodium sulfate. The absorbance of the organic phase (chloroform) was determined at 410 and $479 \mathrm{~nm}$ for BCG and $\mathrm{MO}$, respectively using chloroform as a blank solution. The calibration curves showed the linearity over the concentration ranges $0.5-16$ and $2.0-18 \mu \mathrm{g} \mathrm{mL} \mathrm{L}^{-1}$ for BCG and $\mathrm{MO}$, respectively, Table 1.

Table 1: Quantitative parameters for determination of etilefrine

\begin{tabular}{|c|c|c|}
\hline \multirow{2}{*}{ Parameter } & \multicolumn{2}{|c|}{ Etilefrine } \\
\hline & $B C G$ & MO \\
\hline $\mathrm{pH}$ & 3.0 & 3.5 \\
\hline Extracting solvent & chloroform & chloroforr \\
\hline$\lambda_{\max }$ & 410 & 479 \\
\hline Molar ratio (Drug- $\mathrm{HCl}$ : Dye) & $1: 1$ & $1: 1$ \\
\hline Beer s law limits $\left(\mu \mathrm{g} \mathrm{mL^{-1 } )}\right.$ & $0.5-16$ & $2.0-18$ \\
\hline $\begin{array}{l}\text { Molar absorptivity }\left(\mathrm{L} \mathrm{mol}^{-1} \mathrm{~cm}^{-}\right. \\
\left.{ }^{-}\right)\end{array}$ & $2.4 \times 10^{4}$ & $1.7 \times 10^{6}$ \\
\hline Sandell s sensitivity $\left(\mathrm{ng} \mathrm{cm}^{-<}\right)$ & 9.0 & 13 \\
\hline Range of error \% & $0.44: 0.68$ & $0.55: 0.7$ \\
\hline Regression equation ${ }^{*}$ & & \\
\hline Intercept & 0.01 & 0.04 \\
\hline Slop & 0.112 & 0.077 \\
\hline Correlation coefficient $(r)$ & 0.9998 & 0.9996 \\
\hline & 1.29 & 1.42 \\
\hline F- value $(5.05)^{\star \pi}$ & 2.87 & 2.49 \\
\hline $\operatorname{LOD}\left(\mu \mathrm{g} \mathrm{mL}^{-1}\right)$ & 0.1 & 0.6 \\
\hline $\mathrm{LOQ}\left(\mu \mathrm{g} \mathrm{mL}^{-1}\right)$ & 0.3 & 1.8 \\
\hline $\mathrm{pK}$ & 5.16 & 5.68 \\
\hline
\end{tabular}

\section{Stoichiometric relationship}

Continuous variation was employed using Job's method; $5.0 \times 10^{-4} \mathrm{M}$ solution of BCG and MO 
solution were used. Different solutions were prepared where the total volume of investigated drug and reagent was kept constant at $2 \mathrm{~mL}$. The reagents were mixed in various proportions and completed to $10 \mathrm{~mL}$ mark with distilled water, following the above mentioned procedures.

\section{Assay procedure for tablets}

Ten tablets of Effortil or Vascon (5 mg/tablet) weight crushed and then turn them into powder. The weight amount equal to $5 \mathrm{mg}$ powder of ET

\section{Assay procedure for etilefrine in human plasma}

Samples human plasma were collected in EDTA sample tubes from healthy drug-free volunteers then were spiked with etilefrine. The samples were vortexed and centrifuged at $1500 \mathrm{rpm}$ for $10 \mathrm{~min}$ to separate the plasma components. One milliiter of plasma samples were transferred to a clean sample tube and $1.0 \mathrm{~mL}$ of $\left(100 \mu \mathrm{g} \mathrm{mL}^{-1}\right)$ of standard etilefrine solution was added. The blank prepared in the same manner without the investigated drug then it was used according to the general procedure described above for the quantification of etilefrine concentration.

\section{Computational methodology}

Computational analyses (Density Functional Theory calculations, DFT) were performed using the GAUSSIAN 03 suite of programs [19]. Geometry optimizations of the compounds under investigation were conducted applying the Becke, three-parameter, Lee-Yang-Parr (B3LYP)/6-31G(d) method without any symmetry constraint. No imaginary frequencies were found at the same level of theory to confirm that the geometries of ion pairs were local minima. The interaction energies of the ion-pair formation $(\Delta \mathrm{E})$ under investigation were estimated using the relation in Eq 1.

$\Delta \mathrm{E} \mathrm{kcal} / \mathrm{mol}=627.5\left\{\mathrm{E}_{\mathrm{DR}}(\mathrm{au})-\left(\mathrm{E}_{\mathrm{D}}+\mathrm{E}_{\mathrm{R}}\right)(\mathrm{au})\right\} . .(1)$

where $\Delta \mathrm{E}$ is the energy (in atomic units (au)) of the ion-pair formation and $E_{D R}, E_{D}, E_{R}$ are the energy of ion pair, drug and reagent, respectively.

\section{RESULTS}

Extractive spectrophotometric procedures show widely used due to their sensitivity in the assay of drugs and the quantitative determination of was transferred to a $100 \mathrm{~mL}$ measuring flask containing about $50 \mathrm{~mL}$ of distilled water. The suspended solution was shaken thoroughly for about 10 min., and then filtered through a Whatman filter paper no. 40 to remove insoluble constituents. The separating filtrate was diluted with distilled water to the mark. The described procedure was applied for the quantification of ET concentration using blank solution, which was prepared in the same manner without the investigated drug. A standard additions method was also applied to confirm the precisions and accuracy.

many pharmaceutical compounds [20-23]. Anionic dyes like (BCG and MO) form ionassociation complexes with the positively charged drug. The two oppositely charged ions (drug-dye complex) behave as a single unit, which were attracted together by an electrostatic force.

\section{Optimized reaction conditions}

The extraction and formation process of the coloured compounds of ET with BCG and MO based on $\mathrm{pH}$ value of the solutions, concentration of reagents and the polarity of organic solvent used. The positively charged drug formed ion-association complexes in acidic buffer solution with anionic dyes such as (BCG) and $(\mathrm{MO})$ and these complexes were extracted quantitatively into chloroform. A maximum absorption values of the extracted ion-pair complexes appeared at 410 and $479 \mathrm{~nm}$ for $B C G$ and MO, respectively, as shown in Figure 1. No absorption appeared for the reagent blank under similar conditions.

\section{Effect of $\mathrm{pH}$ and buffer media}

The type and $\mathrm{pH}$ of buffer used play important role for the extraction of the investigated complexes.

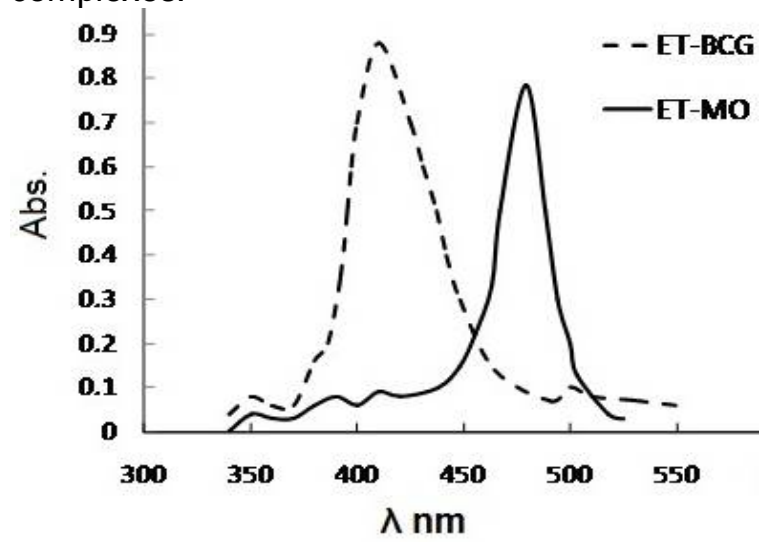

Figure 1: Absorption spectra of ET-BCG and ET-MO ion-pair complexes formed with $10 \mathrm{\mu g} \mathrm{mL}^{-1} \mathrm{ET}$ 


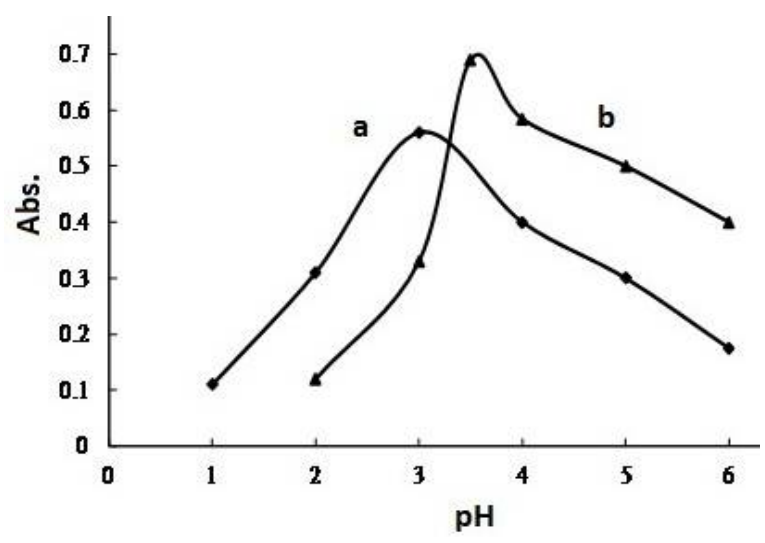

Figure 2: Effect of $\mathrm{pH}$ on the absorbance of ion-pair complexes formed with $10 \mu \mathrm{gL}^{-1}$ ET: a) ET-BCG and b) ET-MO ion-pairs complexes

Different buffers such as (KHPh $-\mathrm{HCl}, \mathrm{pH}=$ 2.22 - 3.58), (NaOAc - HCl, $\mathrm{pH}=2.05-4.82)$, $(\mathrm{NaOAc}-\mathrm{AcOH}, \mathrm{pH}=3.65-5.50)$, and $(\mathrm{B}-\mathrm{R}$ buffer, $\mathrm{pH}=2.0-10$ ) were used to study the effect of $\mathrm{pH}$ for extracting the coloured complexes. The maximum absorbance was observed in B-R buffer solutions of acidic values (Figure 2 and Table 1). The optimum amount of buffer solution used to give constant absorbance was also studied and found to be $5.0 \mathrm{~mL}$.

\section{Effect of dye concentration}

The effect of dyes concentration on the absorbance measurements of the colour developed at optimum wavelengths was tested using different milliliters of $5 \times 10^{-4} \mathrm{M}$ of the dyes. It is apparent from Figure 3 , that the maximum absorbance in each case, was found with $(1.4 \mathrm{~mL})$ of dyestuff, beyond which absorbance was constant. Thus $(2.0 \mathrm{~mL})$ of each dyestuff was used for ion-pair complexes formation during the experiment

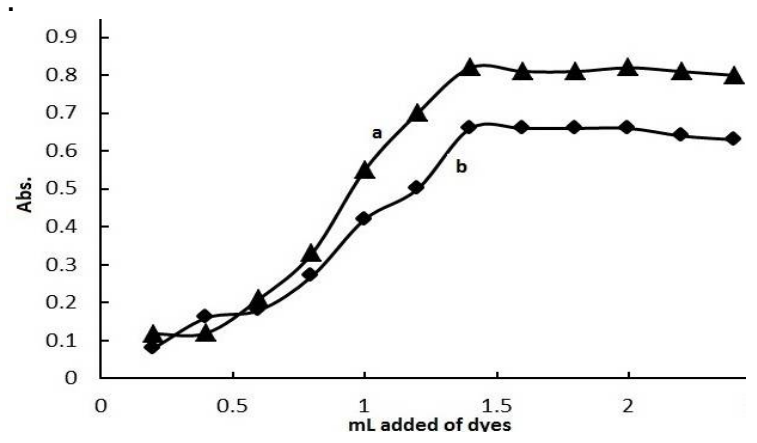

Figure 3: Effect of concentration of the acid dye as $\mathrm{mL}$ added of $1 \times 10^{-3} \mathrm{M} \mathrm{BCG}$ and $\mathrm{MO}$ on the reaction with $10 \mu \mathrm{gL}^{-1} \mathrm{ET}$ : a) ET-BCG and b) ET-MO ionpairs complexes

\section{Selected extracting solvents}

Several organic solvents were tested for effec- tive extraction of the coloured products such as chloroform, dichloromethane, carbon tetrachloride, benzene, and toluene. Maximum absorbance intensities were observed using chloroform which was found to be the most suitable solvent for extraction for all complexes.

\section{Effect of time and temperature}

Shaking time of $1.0-4.0$ min appeared constant absorbance and thus a shaking time of (2.0 min) was preserved during the study to reach equilibrium between both phases. The ratio of aqueous to organic phase was tested and was found not effective and the ratio 1:1 was chosen for extraction of coloured species.

The effect of temperature on the coloured complexes was examined at different temperatures $\left(20,25,30,35\right.$ and $\left.40{ }^{\circ} \mathrm{C}\right)$. It was found that the coloured species were stable up to $40 \stackrel{\circ}{\circ}$. At higher temperatures, increase in drug concentrations was observed due to volatile nature of the organic solvent, which leads to an increase in the absorbance of the products. The coloured species were stable for at least $6 \mathrm{~h}$ at $25^{\circ} \mathrm{C}$.

\section{Composition of ion-pair complexes}

The drug-reagent stoichiometric ratio was found to be $1: 1$ with BCG and $M O$ as detected by Job's (Figure 4) method. The extraction equilibrium can be represented as in Eq 2.

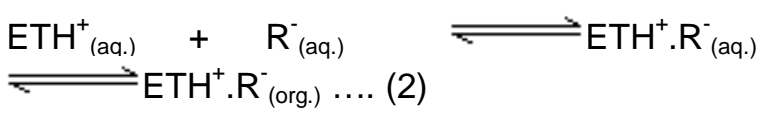

where $\mathrm{ETH}^{+}$and $\mathrm{R}^{-}$represent the protonated etilefrine and the anion of the reagent, respectively. The subscript (org.) and (aq.) refer to the organic and aqueous phases. The proposed methods used to calculate the stoichiometric ratio of the complexes could be used also for the quantification of their stability constant in solution. The values of the stability constant obtained by spectrophotometric methods showed that the complex of with $\mathrm{MO}$ was more stable than BCG reagent (Table 1) which agrees with data obtained by theoretical study.

\section{Analytical performance characteristics}

The Beer-Lambert law limits, Sandell's sensitivity, molar absorptivity, correlation coefficients and regression equations provided by linear square treatment of the results are given in Table 1. Three variant concentrations of ET were prepared and analyzed in six 
measurements and gave satisfactory results to determine the precision and accuracy of the two systems. Subsequently, the ion-pair formations were utilized successfully for their quantification. Percentage relative error (RE \%) as accuracy and percentage relative standard deviation (RSD \%) as precision of the proposed methods were calculated (Table 2). These results of accuracy and precision appeared that the investigated methods have good reproducibility and repeatability. The recoveries and percent relative standard deviation (RSD \%) were found to differ over acceptable ranges (Table 2).

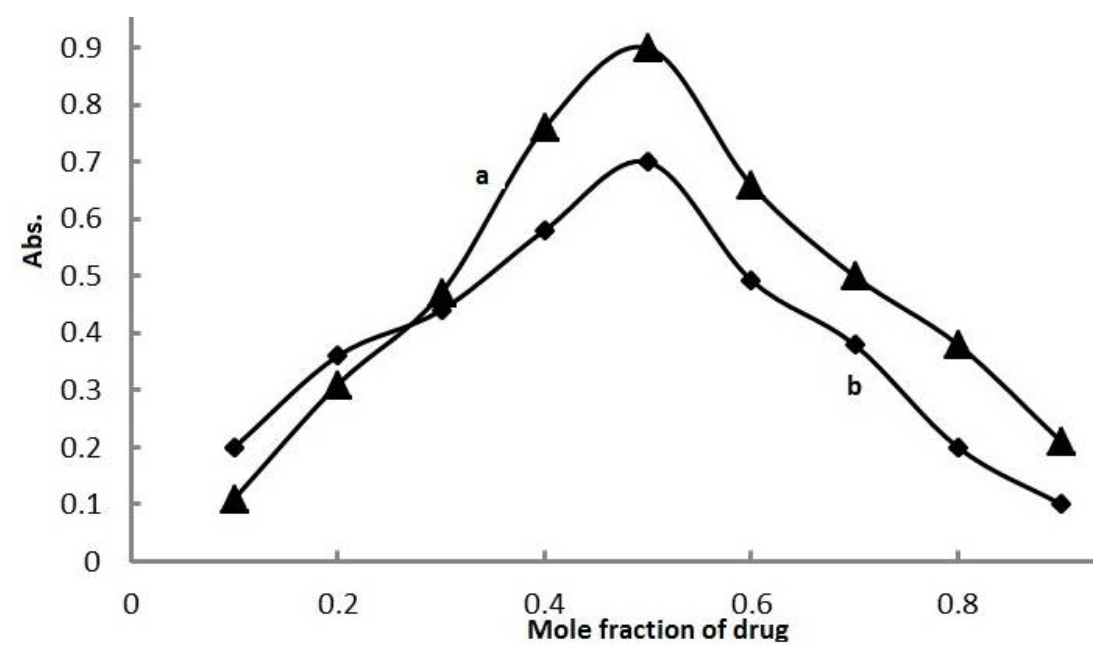

Figure 4: Continuous variation plots for the ion-pair complexes of $10 \mu \mathrm{gmL}^{-1} \mathrm{ET}$ : a) ET-BCG and b) ET-MO ionpairs complexes

Table 2: Evaluation of accuracy and precision for the proposed methods

\begin{tabular}{|c|c|c|c|c|}
\hline Procedure & $\begin{array}{c}\text { Taken } \\
\left(\text { (ugmL }^{-1}\right)\end{array}$ & $\begin{array}{c}\text { Recovery } \\
(\%)\end{array}$ & $\begin{array}{c}\text { RSD } \\
(\%)\end{array}$ & $\begin{array}{l}\text { RE } \\
\text { (\%) }\end{array}$ \\
\hline \multirow{3}{*}{ BCG } & 10.0 & 99.76 & 0.168 & 0.44 \\
\hline & 12.0 & 99.49 & 0.178 & 0.68 \\
\hline & 14.0 & 99.88 & 0.126 & 0.52 \\
\hline \multirow{3}{*}{ MO } & 10.0 & 101.04 & 0.107 & 0.55 \\
\hline & 12.0 & 99.24 & 0.104 & 0.71 \\
\hline & 14.0 & 99.88 & 0.116 & 0.62 \\
\hline
\end{tabular}

Average of six determinations

LOD and LOQ [22] are defined as the lowest amount of detection and that can be accurately quantified (Table 1), respectively. LOD and LOQ were calculated using Eqs 3 and 4.

$L O D=3.3(S D / S)$

$L Q D=10(5 D / 5)$

where SD is the standard deviation of the blank and $S$ is the slope of the standard curve.

\section{Interference}

The influence of common excipients and other additives were examined for possible interferences during determination. It was observed that glucose, talc, sulfate, starch, acetate, phosphate, dextrose, and magnesium stearate did not interfere with the quantification at the concentrations found in pharmaceutical formulations. However, the drug contents were extracted from the drug formulations into chloroform.

\section{Analytical applications}

The proposed method was validated for the analysis of ET in tablets and plasma by analyzing the sample using the proposed method which has been successfully applied to the determination of ET in dosage forms. The data obtained by the investigated methods were compared by official method (Table 3 ). The standard addition method was used to check the recovery and reliability of the proposed methods, since the complexes formation were stable for at least $24 \mathrm{~h}$. The good recoveries refer to that the excipients in dosage forms of ET such as talc, starch, glucose, lactose, sulfate, dextrose, acetate, phosphate, and magnesium stearate were not appeared any exhibits, and any interference during the analysis of investigated drug. 
It is important to monitor etilefrine plasma level in clinical studies due to possible toxicity and its linear elimination pharmacokinetics or inadequate dose after a long treatment. The ability of the proposed method has been estimated through spiking plasma samples with ET at varies concentration levels to determine etilefrine in plasma. It was found that etilefrine could be evaluated with good recoveries (Table 4) at the levels of $8.0-14 \mu \mathrm{gL}^{-1}$ in plasma, thus indicating that there is no interference from excipients.

The results observed for the investigated methods were compared with those obtained using the official method [23]. The calculated Fvalues and Student's t-values did not exceed the theoretical values at $95 \%$ confidence level [22]. Therefore, there is no significant difference between the proposed and official methods.

Table 3: Determination of etilefrine in its formulations using the proposed and official methods (European Pharmacopoeia, monograph 1205, 2012).

\begin{tabular}{|c|c|c|c|c|c|c|c|c|}
\hline \multirow{2}{*}{ Sample } & \multirow[b]{2}{*}{ Method } & \multirow{2}{*}{$\begin{array}{l}\text { Manifested } \\
\text { by }\end{array}$} & \multirow{2}{*}{$\begin{array}{c}\text { Taken } \\
\left(\mu \mathrm{g} \mathrm{mL}^{-1}\right)\end{array}$} & \multirow{2}{*}{$\begin{array}{c}\text { Added } \\
\left(\mu \mathrm{gmL}^{-1}\right)\end{array}$} & \multicolumn{2}{|c|}{ Found } & \multirow{2}{*}{$\begin{array}{c}\text { Recovery } \\
\%\end{array}$} & \multirow{2}{*}{$\begin{array}{c}\text { S.D. } \\
\%\end{array}$} \\
\hline & & & & & Official & Proposed & & \\
\hline \multirow{8}{*}{$\begin{array}{c}\text { Vascon }^{\circledR} \\
5 \text { mg/tablet }\end{array}$} & BCG & & 3.0 & & 2.98 & 2.91 & 97.00 & 0.95 \\
\hline & & Pharma** & & 3.0 & 6.02 & 5.96 & 99.33 & 0.82 \\
\hline & & rmama & & 6.0 & 8.97 & 8.95 & 99.44 & 1.28 \\
\hline & & & & 9.0 & 12.03 & 12.07 & 100.60 & 1.12 \\
\hline & $\mathrm{MO}$ & & 3.5 & & 3.46 & 3.41 & 97.40 & 0.73 \\
\hline & & & & 3.5 & 6.95 & 7.02 & 100.28 & 0.85 \\
\hline & & & & 7.0 & 10.43 & 10.47 & 99.71 & 0.76 \\
\hline & & & & 10.5 & 14.05 & 13.96 & 99.71 & 0.58 \\
\hline
\end{tabular}

*Mean of six determinations; ${ }^{\star *}$ El-Obour City, Egypt

Table 4: Precision and recovery of etilefrine in spiked human plasma

\begin{tabular}{|c|c|c|c|c|}
\hline \multirow{2}{*}{$\begin{array}{l}\text { Added } \\
(\mu \mathrm{g} / \mathrm{mL})\end{array}$} & \multicolumn{2}{|c|}{ Recovery (\%) ${ }^{*}$} & \multicolumn{2}{|c|}{ RSD (\%) } \\
\hline & $E T-B C G$ & $E T-M O$ & $E T-B C G$ & ET-MO \\
\hline 8.0 & 91.2 & 78.6 & 1.2 & 1.1 \\
\hline 10.0 & 89.5 & 77.7 & 0.5 & 0.9 \\
\hline 12.0 & 90.8 & 87.6 & 0.3 & 0.7 \\
\hline 14.0 & 94.3 & 91.5 & 0.1 & 0.2 \\
\hline
\end{tabular}

${ }^{\star}$ Mean of five measurements

\section{DISCUSSION}

Figure 5 and Figure 6 show the optimized geometries of the drug, reagents and the ion pairs formed as calculated in our study along with their atom numbering. The structural analysis reveals the presence of intermolecular hydrogen bond interactions in the ion pairs formed between ET and BCG and MO expressed in the $(\mathrm{NH} . . . . \mathrm{O})$.
The structural parameters, global minimum energy, dipole moments as well as the interaction energies obtained for the optimized geometry of all interacting species as well as the ion pairs formed as obtained from the B3LYP/6$31 \mathrm{G}(\mathrm{d})$ basis sets are presented in Table 5. The ET-MO ion pair is found to have larger interaction energy (higher stability) than the ET-BCG ion pair as inferred from their interaction energy values as indicated in Table 5. 


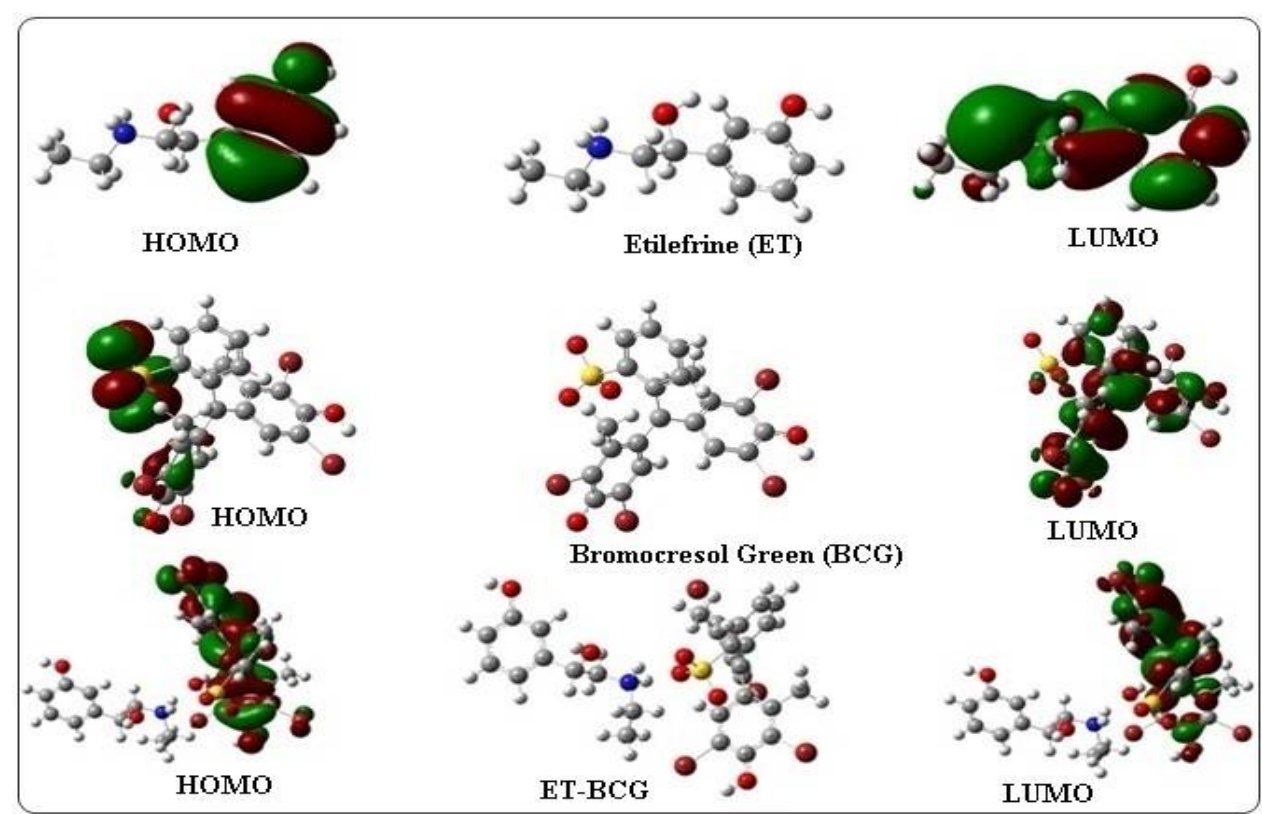

Figure 5: The optimized structures of the 1:1 ion pair of ET with BCG and their HOMO and LUMO orbitals by the B3LYP/6-31G(d)

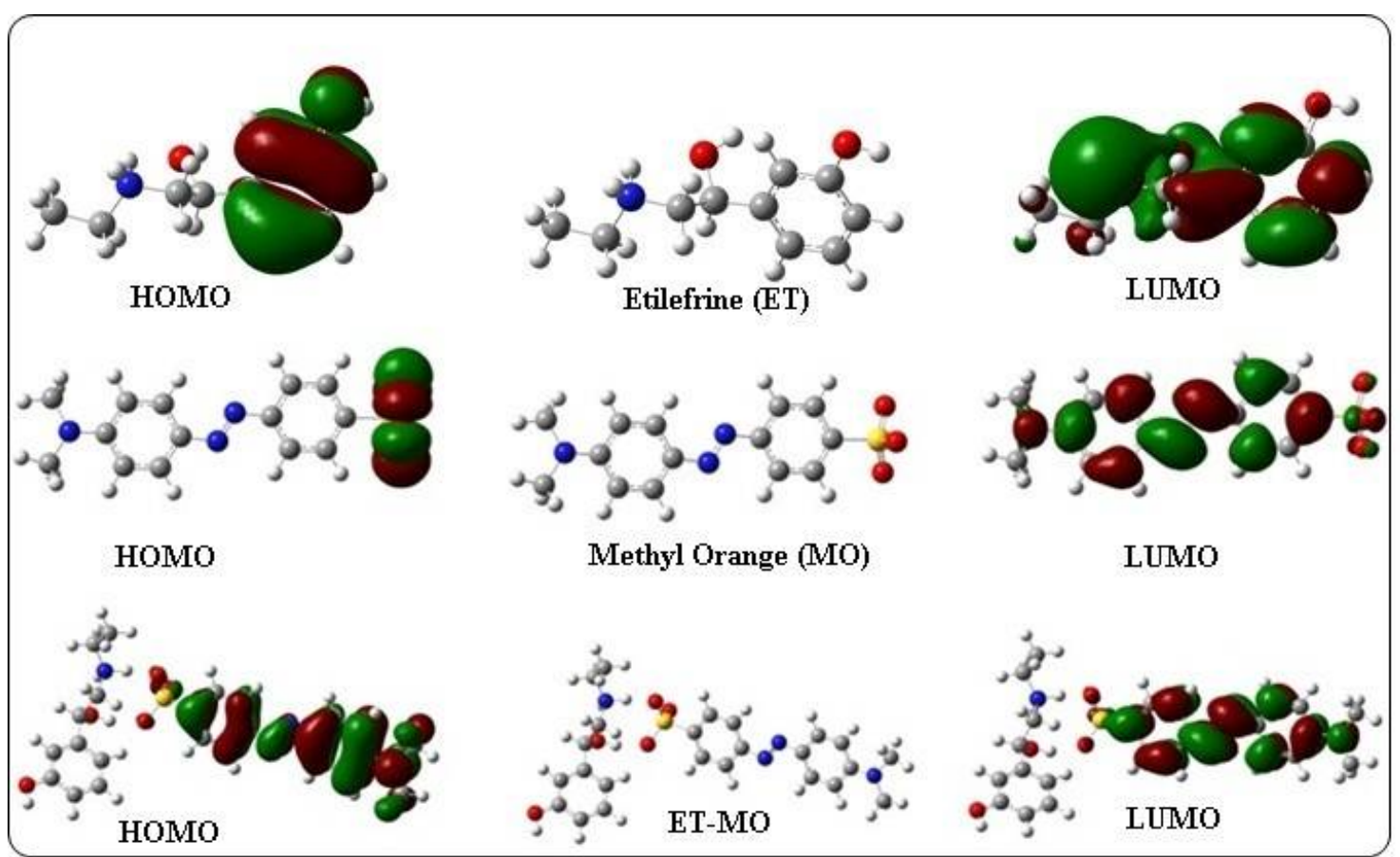

Figure 6: The optimized structures of the 1:1 ion pair of ET with MO and their HOMO and LUMO orbitals by the B3LYP/6-31G(d) approach

As inferred from Table 5 , the changes in the geometrical parameters of the interacting species upon the ion pair formation is related to the active sites involved in the interaction. The most significantly changed are the bonds involved in the hydrogen bonding. For the ET drug, the bonds involved in the hydrogen bonding are $\mathrm{N} 10 \mathrm{H} 22, \mathrm{~N} 10 \mathrm{H} 29$ (with BCG) and $\mathrm{O} 11 \mathrm{H} 23$ (with $\mathrm{MO}$ ). The calculated changes of the bonds show that, as a result of the hydrogen bonding, the bonds $\mathrm{N} 10 \mathrm{H} 22$ (with $\mathrm{BCG}$ ), $\mathrm{O} 11 \mathrm{H} 23$ (with $\mathrm{MO}$ ) become longer. The lengthening of the bonds depends on the strength of the corresponding hydrogen bonds. Concerning the $\mathrm{SO} 3$ group in BCG reagent which is also involved during the hydrogen bonding interaction in the ion pair formation, the r(S14-015) and r(S14-042) bonds showed lengthening whereas the bond r(S14O43) showed bond shortening (Table 5a). The same behavior observed for the $\mathrm{S}-\mathrm{O}$ bonds in the SO3 group in the methyl orange (Table 5).

The hydrogen bonds in the ET-BCG found to be rN9-H22...O15 (1.673') and rN9- H29...O44 
Table 5: Selected structural parameters of the different drug reagents and the two ion pairs

\begin{tabular}{|c|c|c|c|c|c|}
\hline $\begin{array}{l}\text { Structural } \\
\text { Parameters } \\
\end{array}$ & $(E T)$ & (BCG) & (MO) & (ET-BCG) & (ET-MO) \\
\hline \multicolumn{6}{|c|}{ Bond lengths (rÅ), bond angles (deg), dihedral angles $(r$, deg) } \\
\hline $\begin{array}{l}r(9-10) \\
r(10-12) \\
r(10-22) \\
r(10-29) \\
r N 10-H 22 \ldots O 15 \\
r N 10-H 29 \ldots .042\end{array}$ & $\begin{array}{l}1.518 \\
1.515 \\
1.025 \\
1.034\end{array}$ & & & $\begin{array}{l}1.491 \\
1.505 \\
1.062 \\
1.035 \\
1.681 \\
2.048\end{array}$ & $\begin{array}{l}1.506 \\
1.494 \\
1.079 \\
1.035\end{array}$ \\
\hline$<(9-10-22)$ & 110.0 & & & 110.8 & 107.4 \\
\hline$<(9-10-29)$ & 104.4 & & & 109.9 & 104.3 \\
\hline$<(12-10-22)$ & 108.9 & & & 108.4 & 110.3 \\
\hline$<(12-10-29)$ & 109.2 & & & 107.4 & 112.0 \\
\hline$<(22-10-29)$ & 107.5 & & & 100.4 & 104.2 \\
\hline т22-10-12-9 & -125.0 & & & -127.2 & -123.6 \\
\hline т 29-10-12-9 & 117.9 & & & 125.1 & 120.8 \\
\hline$r(13-14)$ & & 1.843 & & 1.812 & \\
\hline$r(14-15)$ & & 1.490 & & 1.520 & \\
\hline$r(14-42)$ & & 1.482 & & 1.496 & \\
\hline$r(14-43)$ & & 1.485 & & 1.476 & \\
\hline$<(13-14-15)$ & & 103.9 & & 104.5 & \\
\hline$<(13-14-42)$ & & 103.5 & & 105.7 & \\
\hline$<(13-14-43)$ & & 104.1 & & 108.3 & \\
\hline$<(15-14-42)$ & & 114.6 & & 110.1 & \\
\hline$<(15-14-43)$ & & 114.2 & & 113.4 & \\
\hline$<(42-14-43)$ & & 114.7 & & 114.1 & \\
\hline т (15-14-13-12) & & 136.8 & & 136.8 & \\
\hline т (42-14-13-12) & & 16.8 & & 20.7 & \\
\hline $\mathrm{T}(43-14-13-12)$ & & -103.4 & & -101.9 & \\
\hline$r(15-18)$ & & & 1.823 & & 1.794 \\
\hline$r(18-19)$ & & & 1.486 & & 1.472 \\
\hline$r(18-20)$ & & & 1.487 & & 1.506 \\
\hline$r(18-21)$ & & & 1.487 & & 1.520 \\
\hline rO11-C8 & & & & & 1.421 \\
\hline rO11-H23...O49 & & & & & 1.796 \\
\hline rN10-H22...O50 & & & & & 1.569 \\
\hline \multicolumn{6}{|c|}{ TBond angles (deg), dihedral angles ( $r$, deg), and interaction energies $\Delta E_{\text {interaction }}(\mathrm{kcal} / \mathrm{mol})$} \\
\hline$<\mathrm{O} 8-\mathrm{C} 11-\mathrm{H} 23$ & & & & & 109.2 \\
\hline$<(15-18-19)$ & & & 103.9 & & 108.8 \\
\hline$<(15-18-20)$ & & & 103.2 & & 105.2 \\
\hline$<(15-18-21)$ & & & 103.6 & & 104.3 \\
\hline$<(19-18-20)$ & & & 114.6 & & 114.3 \\
\hline$<(19-18-21)$ & & & 115.0 & & 113.2 \\
\hline$<(20-18-21)$ & & & 114.4 & & 110.2 \\
\hline т 48-47-44-43 & & & 155.9 & & -90.1 \\
\hline т 49-47-44-43 & & & -84.3 & & 32.7 \\
\hline т 50-47-44-43 & & & 35.4 & & 148.8 \\
\hline Energy & 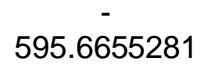 & 11869.186431 & -1330.001024 & 12464.998024 & -1925.834876 \\
\hline $\begin{array}{c}\text { Dipole moment } \\
\mu(\text { debye })\end{array}$ & 8.8362 & 15.1863 & 15.5170 & 13.0903 & 7.2509 \\
\hline $\begin{array}{l}\Delta \mathrm{E}_{\text {imteraction }} \\
\mathrm{Kcal} / \mathrm{mol}\end{array}$ & & & & -91.654 & -105.623 \\
\hline
\end{tabular}

$(2.048$ ') with the $\mathrm{rN9}-\mathrm{H} 22 \ldots \mathrm{O} 15$ to be the strongest (Table 5). The values for theses hydrogen bonds shorter and coincide with the van der Waals distance of reported hydrogen bonded O...H [24]. For the ET-MO ion pair (Figure 6), the hydrogen bonds $\mathrm{rO11-H23...049}$ and rN10-H22...050 were found to be with a bond length values equal to $1.796{ }^{\prime}$ and 1.569 respectively.

These values show a strong hydrogen bonding compared to that of the ET-BCG ion pair. This is in agreement with the interaction energies obtained for the two ion pairs [24]. 
Table 6: Atomic charge for the interacting atomic sites

\begin{tabular}{|c|c|c|c|c|c|}
\hline Atom & ET & BCG & ET-BCG & MO & ET-MO \\
\hline N10 & -0.620 & & -0.650 & & -0.657 \\
\hline H22 & 0.463 & & 0.486 & & 0.487 \\
\hline $\mathrm{H} 29$ & 0.484 & & 0.494 & & 0.463 \\
\hline C12 & -0.262 & & -0.272 & & -0.260 \\
\hline S14 & & 2.448 & 2.425 & & \\
\hline 015 & & -1.015 & -1.040 & & \\
\hline O42 & & -1.003 & -1.030 & & \\
\hline O43 & & -1.010 & -0.975 & & \\
\hline C13 & & -0.274 & -0.279 & & \\
\hline S18 & & & & 2.440 & 2.438 \\
\hline 019 & & & & -1.026 & -0.961 \\
\hline $\mathrm{O} 20$ & & & & -1.007 & -1.056 \\
\hline $\mathrm{O} 21$ & & & & -1.023 & -1.034 \\
\hline C15 & & & & -0.272 & -0.310 \\
\hline
\end{tabular}

The changes in the angles with the ion pair formation were also estimated. The results depicted in Table 5 show that the angles between the atoms involved in the hydrogen bonding in the ET-BCG ion pair formation specially the (22-10-29) bond angle is showing 7 degrees change. Some of the dihedral angles also of the atoms taking part in the ion pair formation show a change in their values such as T (42-14-13-12) and $T$ (43-14-13-12) that deviates with $\mathrm{a} \sim 2$ - 4 degrees in the ion pair compared to the corresponding value in the drug. In the ET-MO ion pair some of the bond angles concerning the interactive atomic sites are showing the same trend, whereas the dihedral angles are showing a larger deviation (Table 5). The strength of the hydrogen bonding controls the changes in the angles. The remaining geometrical parameters either changed with small values or stayed unchanged upon the formation of hydrogen bonds. The large values of the dipole moment of the interacting species explain the electrostatic interaction between these species (Table 5).

\section{Atomic charge analysis}

The charge distribution on a molecule has a significant influence on the chemical reactivity and can be used to explain the differences in hydrogen bonding and electrostatic interaction $[25,26]$. The Full NBO atomic charges as obtained for the atoms at the interacting sites at B3LYP level using Gaussian03, with the 6$31 \mathrm{G}(\mathrm{d})$ atomic basis set are depicted in Table 6. It is worthy to mention that, the nitrogen atom $\mathrm{N} 10$ atomic charge has been increased upon the interaction between ET and BCG reagent from 0.620 up to -0.650 with an increase in the positive charge for the hydrogen atoms $\mathrm{H} 22$ and $\mathrm{H} 29$ from 0.463 and 0.484 to 0.486 and 0.494 respectively. In the ET-BCG ion pair, two out of three oxygen atoms in the $\mathrm{SO} 3$ group show an increase in the charge upon ion pair formation whereas the third atom $\mathrm{O} 44$ shows a decrease in the charge from -1.005 to -0.977 . The same trend was found for the ET-MO ion pair (Table 6).

\section{HOMO/LUMO energy values and energy gap}

One of the main criteria when dealing with the interaction of molecular orbitals, is that the two orbitals that interact are generally the Highest Occupied Molecular Orbital (HOMO) of one molecule and the Lowest Unoccupied Molecular Orbital (LUMO) of another molecule.

HOMO and LUMO are also known as frontier orbitals and they are essential in determining the amount of energy required to accept or lose electrons in a molecule. HOMO is associated with the tendency of a species to donate electron and is characteristic for nucleophile components while LUMO is associated with the tendency to receive electrons, and is characteristic for electrophilic components. Ionization potential (I) is defined as the ability of a ligand to donate precisely an electron to an acceptor while electron affinity $(A)$ is defined as the ability of a ligand to accept precisely an electron from a donor. HOMO energy is related to the ionization potential as approximated by Koopmans's theorem while LUMO energy is used to estimate the electron affinity [27].

As anions have the tendency to donate electrons, thus anions with lower HOMO energy values are better electron donors. By careful inspection of Table 7, Figure 5 and Figure 6, one can decide that the species with low HOMO energy indicates high ionization potential of a species (better electron donor) while those with high LUMO energy indicate high electron affinity (better electron acceptor). Global reactivity indexes can be used to evaluate and predict the chemical reactivity and the selectivity of molecular systems for being electron donors or acceptors during molecular interaction. The 
electronegativity which is defined as the ability to attract electrons by the molecule can be obtained as $\mathrm{X}=-\mathrm{E}_{\mathrm{HOMO}}-\mathrm{E}_{\mathrm{LUMO}} / 2=\mathrm{I}-\mathrm{A} / 2$. A property that depends on the electronegativity is the chemical potential $(\mu)$ which is considered as the negative of the electronegativity. The HOMOLUMO energy gap can be determined and further, the important properties in quantum chemical calculation such as the hardness $(\eta)$, softness $(S)$, chemical potential $(\mu)$, electronegativity $(X)$ and electrophilicity index $(\omega)$ can be obtained. The hardness of a molecule $(\eta)$ is related to the $E_{\mathrm{LUMO}}-\mathrm{E}_{\mathrm{HOMO}}$ energy gap by the following eq. (5):

$2 \eta=E_{\text {LMO }}-E_{\text {MOMO }}=Z-A$

Where the softness $(\boldsymbol{S})$, calculated according to eq. (6):

$$
s=1 / \eta=\frac{2}{R_{\text {LUMD }}-R_{\text {HOMO }}}=2 / 2-A
$$

(Where, $(\mathrm{I})$ is the ionization potential and $(\mathrm{A})$ is the electron affinity).

The electophilicity index $(\omega)=\mu^{2} / 2 \eta$, that reflects the stability of the molecule when it accepts electrons from the surrounding.

Careful inspection of Table 7 shows that, etilefrine molecule is going to accept electrons and the two reagents are going to be electron donors. $\mathrm{MO}$ is going to be a better nucleophile than BCG, which is in good agreement with the interaction energies and the HOMO and LUMO Eigen values.
The electrostatic potential surface (ESP) is an effective tool for predicting and analyzing noncovalent interactions [28 - 30]. As can be seen in Figure 7, the high positively charged region in the etilefrine molecule is around the $\mathrm{N} 10-\mathrm{H}$ group whereas the highly negative regions are found to be around the oxygen atoms in the $\mathrm{SO} 3$ sulphonate group. This further supports the sites of interaction between the etilefrine molecule and the two reagents.

\section{NBO analyses}

Natural bond orbital (NBO) analysis was performed on ET-BCG and ET-MO ion pairs at the B3LYP level as implemented in the Gaussian program package. The most significant interactions between filled (donor) Lewis-type NBOs and empty (acceptor) non-Lewis NBOs for the two ion pairs ET-BCG and ET-MO are reported in Table 8 and Table 9 respectively. In addition, the stabilization energy associated with these bonds calculated by NBO analysis is also given.

The stabilization energy $E^{(2)}$ associated with delocalization is estimated using the second order perturbation theory as in eq. (7):

$E^{(2)}=-q_{i} \frac{\left(F_{i j}\right)^{2}}{z_{j}-z_{i}}$

where the donor orbital occupancy is denoted as qi, the diagonal elements, $\varepsilon_{i}$ and $\varepsilon_{j}$, are the orbital energies, and $F_{i j}$ is the off-diagonal NBO Fock (Kohn-Sham matrix element) [31]. The large

Table 7: Calculated $E_{\mathrm{HOMO}}, E_{\mathrm{LUMO}}, \Delta E$ energy band gap $\left(\mathrm{E}_{\mathrm{L}}-\mathrm{E}_{\mathrm{H}}\right)$, lonization potential $(\Lambda)$, Electron affinity $(A)$, electronegativity $(X)$, chemical potential $(\mu)$, global hardness $(\eta)$, global softness $(S)$ and global electrophilicity index $(\omega)$ for ET and the reagents as obtained from the B3LYP/6-31G(d) calculation

\begin{tabular}{lcccccccccc}
\hline Compound & $\boldsymbol{E}_{\mathrm{H}}(\mathbf{e v})$ & $\boldsymbol{E}_{\mathrm{L}}(\mathbf{e v})$ & $\begin{array}{c}\boldsymbol{\Delta} \text { Egab } \\
(\mathbf{e v})\end{array}$ & $\boldsymbol{I}$ & $\boldsymbol{A}$ & $\boldsymbol{X}$ & $\boldsymbol{\eta}$ & $\boldsymbol{S}$ & $\boldsymbol{\mu}$ & $\boldsymbol{\omega}$ \\
\hline ET & -9.0058 & -3.5895 & 5.4163 & 9.0058 & 3.5895 & 6.2977 & 2.7081 & 0.3693 & -6.2977 & 19.8615 \\
BCG & -2.8997 & -0.3108 & 2.5890 & 2.8997 & 0.3108 & 1.6052 & 1.2945 & 0.7725 & -1.6052 & 2.1691 \\
MO & -1.9579 & 0.5034 & 2.4613 & 1.9579 & -0.5034 & 0.7272 & 1.2307 & 0.8126 & -0.7272 & 1.8639 \\
ET-BCG & -5.6598 & -2.6281 & 3.0317 & 5.6598 & 2.6281 & 4.1440 & 1.5158 & 0.6600 & -4.1440 & 3.4831 \\
ET-MO & -5.0715 & -1.7669 & 3.3046 & 5.0715 & 1.7669 & 3.4192 & 1.6523 & 0.6052 & -3.4192 & 4.5110 \\
\hline
\end{tabular}

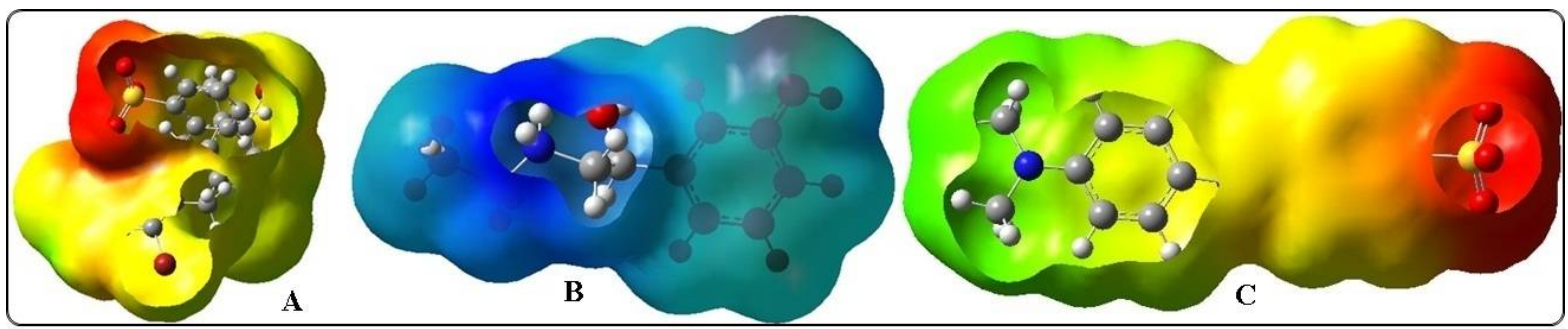

Figure 7: Electrostatic potential surfaces for interacting molecules, A) Bromocresol Green, B) Etilefrine, C) Methyl orange. Where the red and blue colours indicate regions of more negative and positive charges, respectively, and the isodensity contours are 0.02 electron/bohr. 
Table 8: Second-order perturbation theory analysis of Fock matrix on NBO basis for ion pair (ET-BCG) by using the B3LYP method with the 6-31G(d) basis set

\begin{tabular}{|c|c|c|c|c|}
\hline Donor NBO (i) & Acceptor NBO (j) & $E(2) \mathrm{kcal} / \mathrm{mol}$ & $E(j)-E(i)$ a.u. & $F(i, j)$ a.u. \\
\hline$\pi(\mathrm{C} 1-\mathrm{C} 3)$ & $\pi^{*}(\mathrm{C} 2-\mathrm{C} 6)$ & 21.96 & 0.28 & 0.072 \\
\hline$\pi(\mathrm{C} 1-\mathrm{C} 3)$ & $\pi^{*}(\mathrm{C} 4-\mathrm{C} 5)$ & 17.04 & 0.29 & 0.063 \\
\hline$\pi(\mathrm{C} 2-\mathrm{C} 6)$ & $\Pi^{*}(\mathrm{C} 1-\mathrm{C} 3)$ & 17.40 & 0.29 & 0.063 \\
\hline$\pi(\mathrm{C} 2-\mathrm{C} 6)$ & $\Pi^{*}(\mathrm{C} 4-\mathrm{C} 5)$ & 23.15 & 0.29 & 0.073 \\
\hline$\pi(\mathrm{C} 4-\mathrm{C} 5)$ & $\pi^{*}(\mathrm{C} 1-\mathrm{C} 3)$ & 22.90 & 0.28 & 0.072 \\
\hline$\pi(\mathrm{C} 4-\mathrm{C} 5)$ & $\pi^{*}(\mathrm{C} 2-\mathrm{C} 6)$ & 17.13 & 0.28 & 0.062 \\
\hline $\mathrm{n} 2(\mathrm{O} 7)$ & $\pi^{*}(\mathrm{C} 2-\mathrm{C} 6)$ & 30.08 & 0.34 & 0.097 \\
\hline n3(O44) & $\sigma^{*}(\mathrm{~N} 10-\mathrm{H} 22)$ & 28.32 & 0.65 & 0.124 \\
\hline$\pi(\mathrm{C} 31-\mathrm{C} 32)$ & $\pi^{*}(\mathrm{C} 30-058)$ & 19.20 & 0.31 & 0.071 \\
\hline$\pi(\mathrm{C} 31-\mathrm{C} 32)$ & $\pi^{*}(\mathrm{C} 33-\mathrm{C} 36)$ & 12.04 & 0.31 & 0.056 \\
\hline$\pi($ C33-C36) & $\pi^{*}(\mathrm{C} 31-\mathrm{C} 32)$ & 20.46 & 0.29 & 0.070 \\
\hline$\pi($ C33-C36) & $\pi^{*}(\mathrm{C} 34-\mathrm{C} 35)$ & 16.43 & 0.29 & 0.063 \\
\hline т(C34-C35) & $\pi^{*}(\mathrm{C} 30-\mathrm{O} 58)$ & 19.15 & 0.31 & 0.070 \\
\hline$\pi(C 34-C 35)$ & $\pi^{*}(\mathrm{C} 33-\mathrm{C} 36)$ & 12.17 & 0.31 & 0.055 \\
\hline т(C37-C38) & $\pi^{*}(\mathrm{C} 39-\mathrm{C} 40)$ & 19.82 & 0.28 & 0.068 \\
\hline$\pi(\mathrm{C} 37-\mathrm{C} 38)$ & $\Pi^{*}(\mathrm{C} 41-\mathrm{C} 42)$ & 18.45 & 0.28 & 0.064 \\
\hline$\pi(C 39-C 40)$ & $\pi^{*}(\mathrm{C} 37-\mathrm{C} 38)$ & 21.72 & 0.28 & 0.069 \\
\hline п(C39-C40) & $\pi^{*}(\mathrm{C} 41-\mathrm{C} 42$ & 21.85 & 0.28 & 0.070 \\
\hline п(C41-C42) & $\Pi^{*}(\mathrm{C} 37-\mathrm{C} 38)$ & 20.11 & 0.28 & 0.068 \\
\hline п(C41-C42) & $\Pi^{*}(\mathrm{C} 39-\mathrm{C} 40)$ & 18.58 & 0.29 & 0.065 \\
\hline$\pi(C 45-C 46)$ & $\Pi^{*}(\mathrm{C} 47-\mathrm{C} 48)$ & 17.85 & 0.25 & 0.061 \\
\hline$\pi(C 45-C 46)$ & $\pi^{*}(\mathrm{C} 49-\mathrm{C} 50)$ & 24.42 & 0.27 & 0.073 \\
\hline$\pi(\mathrm{C} 47-\mathrm{C} 48)$ & $\pi^{*}(\mathrm{C} 45-\mathrm{C} 46)$ & 23.90 & 0.31 & 0.078 \\
\hline$\pi$ (C47-C48) & $\pi^{*}(\mathrm{C} 49-\mathrm{C} 50)$ & 13.41 & 0.30 & 0.058 \\
\hline п (C49-C50) & $\pi^{*}(\mathrm{C} 45-\mathrm{C} 46)$ & 14.07 & 0.29 & 0.058 \\
\hline$\pi$ (C49-C50) & $\Pi^{*}(\mathrm{C} 47-\mathrm{C} 48)$ & 25.24 & 0.27 & 0.076 \\
\hline $\mathrm{n} 2(\mathrm{O} 44)$ & $\sigma^{*}(\mathrm{~S} 43-\mathrm{O} 33)$ & 17.49 & 0.58 & 0.091 \\
\hline n3(O44) & $\sigma^{*}(\mathrm{C} 42-\mathrm{S} 43)$ & 12.69 & 0.47 & 0.069 \\
\hline $\mathrm{n} 2(\mathrm{O} 52)$ & $\Pi^{*}(\mathrm{C} 47-\mathrm{C} 48)$ & 35.35 & 0.33 & 0.104 \\
\hline $\mathrm{n} 2(\mathrm{O} 58)$ & $\pi^{*}(\mathrm{C} 30-\mathrm{C} 31)$ & 21.03 & 0.69 & 0.109 \\
\hline $\mathrm{n} 2(\mathrm{O} 58)$ & $\pi^{*}(\mathrm{C} 30-\mathrm{C} 35)$ & 21.76 & 0.68 & 0.110 \\
\hline $\mathrm{n} 2(\mathrm{O} 71)$ & $\sigma^{*}(\mathrm{~S} 43-044)$ & 10.47 & 0.52 & 0.067 \\
\hline n2 (O71) & $\sigma^{*}(\mathrm{~S} 43-073)$ & 18.57 & 0.57 & 0.092 \\
\hline n3 (O71) & $\sigma^{*}(\mathrm{C} 42-\mathrm{S} 43)$ & 16.88 & 0.44 & 0.078 \\
\hline n2 (O72) & $\sigma^{*}(\mathrm{~S} 43-044)$ & 11.91 & 0.50 & 0.069 \\
\hline $\mathrm{n} 2(\mathrm{O} 72)$ & $\sigma^{*}(S 43-072)$ & 21.52 & 0.53 & 0.096 \\
\hline n3 (O72) & $\sigma^{*}(\mathrm{C} 42-\mathrm{S} 43)$ & 18.59 & 0.42 & 0.080 \\
\hline n3 (O72) & $\sigma^{*}(\mathrm{~S} 43-044)$ & 12.03 & 0.51 & 0.070 \\
\hline
\end{tabular}

$E(2)$ value indicates the more strong interaction between the electron donors and electron acceptors. Relatively high stabilization energies of the $\pi \rightarrow \pi^{*}$ as seen in Table 8 and Table 9 for both ion pairs indicate strong delocalization of the $\pi$ electrons which leads to stabilization of the molecule. Concerning the ET-BCG ion pair, Table 8, the maximum values were shown as $\pi(\mathrm{C} 33-\mathrm{C} 36) \rightarrow \pi^{*}(\mathrm{C} 31-\mathrm{C} 32), \pi(\mathrm{C} 45-\mathrm{C} 46) \rightarrow$ $\pi^{*}(\mathrm{C} 49-\mathrm{C} 50)$ and $\pi(\mathrm{C} 45-\mathrm{C} 46) \rightarrow \pi^{*}(\mathrm{C} 47$ C48) with a stabilizing values of $20.46,24.42$ and $25.24 \mathrm{kcal} / \mathrm{mol}$ respectively. The hyper conjugative interaction concerning the interaction between the lone pairs n2(O7), n3(O44), $\mathrm{n} 2(\mathrm{O52}), \mathrm{n} 2(\mathrm{O58})$ and $\mathrm{n} 2(\mathrm{O58})$ to the antibonding orbitals $\pi^{*}(\mathrm{C} 2-\mathrm{C} 6), \sigma^{*}(\mathrm{~N} 10-\mathrm{H} 22)$, $\Pi^{*}(\mathrm{C} 47-\mathrm{C} 48), \pi^{*}(\mathrm{C} 30-\mathrm{C} 31)$ and $\pi^{*}(\mathrm{C} 30-\mathrm{C} 35)$ respectively. These interactions show stabilizing energies of $30.08,28.32,35.35,21.03$ and 21.76 $\mathrm{kcal} / \mathrm{mol}$, respectively. The $\mathrm{n} 3(\mathrm{O} 44) \rightarrow \sigma^{*}(\mathrm{~N} 10-$ $\mathrm{H} 22)$ with a large stabilization energies indicating a strong hydrogen bond which leads to weakness of the bond $\mathrm{N} 10-\mathrm{H} 22$. This accounts to its increase in the ion pair ET-BCG (Table 5).

Concerning the ET-MO ion pair, the interactions between the $\pi(\mathrm{C} 1-\mathrm{C} 3) \rightarrow \pi^{*}(\mathrm{C} 2-\mathrm{C} 6), \quad \pi(\mathrm{C} 4-$ $\mathrm{C5}) \rightarrow \pi^{*}$ (C1-C3), $\quad \pi(\mathrm{C} 34-\mathrm{C} 35) \rightarrow \pi^{*}(\mathrm{~N} 39-\mathrm{N} 40)$ and $\pi(\mathrm{C} 31-\mathrm{C} 36) \rightarrow \pi^{*}(\mathrm{C} 34-\mathrm{C} 35)$ shows the maximum stabilization energies with the values of 22.49, 22.66, 23.77 and $25.89 \mathrm{kcal} / \mathrm{mol}$ respectively (Table 9 ). These high stabilization energies accounts for the high stability of the molecule. A hyper conjugative interaction was observed from the lone pair of N30 and O7 to the antibonding orbitals of (C31-C36) and (C2-C6) respectively and stabilizing these rings with stabilizing energy values of 46.27 and 28.81 $\mathrm{kcal} / \mathrm{mol}$ respectively. The conjugation of lone pair of $\mathrm{n} 3(\mathrm{O} 49)$ with $\sigma^{*}(\mathrm{O} 11-\mathrm{H} 23)$ was also observed $(12.42 \mathrm{kcal} / \mathrm{mol})$. This interaction 
Table 9: Second-order perturbation theory analysis of Fock matrix on NBO basis for ion pair (ET-MO) by using the B3LYP method with the 6-31G(d) basis set

\begin{tabular}{|c|c|c|c|c|}
\hline Donor NBO (i) & Acceptor NBO (j) & $E(2) \mathrm{kcal} / \mathrm{mol}$ & $E(j)-E(i)$ a.u. & F(i,j)a.u. \\
\hline$\pi(\mathrm{C} 1-\mathrm{C} 3)$ & $\pi^{*}(\mathrm{C} 2-\mathrm{C} 6)$ & 22.49 & 0.28 & 0.072 \\
\hline$\pi(\mathrm{C} 1-\mathrm{C} 3)$ & $\Pi^{*}(\mathrm{C} 4-\mathrm{C} 5)$ & 16.79 & 0.29 & 0.063 \\
\hline$\pi(\mathrm{C} 2-\mathrm{C} 6)$ & $\pi^{*}(\mathrm{C} 1-\mathrm{C} 3)$ & 16.75 & 0.30 & 0.063 \\
\hline$\pi(\mathrm{C} 2-\mathrm{C} 6)$ & $\Pi^{*}(\mathrm{C} 4-\mathrm{C} 5)$ & 21.68 & 0.30 & 0.072 \\
\hline$\pi(\mathrm{C} 4-\mathrm{C} 5)$ & $\pi^{*}(\mathrm{C} 1-\mathrm{C} 3)$ & 22.66 & 0.28 & 0.072 \\
\hline$\pi(\mathrm{C} 4-\mathrm{C} 5)$ & $\pi^{*}(\mathrm{C} 2-\mathrm{C} 6)$ & 17.93 & 0.27 & 0.063 \\
\hline $\mathrm{n} 2(\mathrm{O} 7)$ & $\pi^{*}(\mathrm{C} 2-\mathrm{C} 6)$ & 28.81 & 0.35 & 0.096 \\
\hline n3(O49) & $\sigma^{*}(011-H 23)$ & 12.42 & 0.71 & 0.086 \\
\hline$\pi(\mathrm{C} 31-\mathrm{C} 36)$ & $\pi^{*}(\mathrm{C} 32-\mathrm{C} 33)$ & 13.84 & 0.29 & 0.058 \\
\hline$\pi(\mathrm{C} 31-\mathrm{C} 36)$ & $\pi^{*}(\mathrm{C} 34-\mathrm{C} 35)$ & 25.89 & 0.29 & 0.077 \\
\hline$\pi(\mathrm{C} 32-\mathrm{C} 33)$ & $\pi^{*}(\mathrm{C} 31-\mathrm{C} 36)$ & 20.72 & 0.27 & 0.070 \\
\hline$\pi(\mathrm{C} 32-\mathrm{C} 33)$ & $\pi^{*}(\mathrm{C} 34-\mathrm{C} 35)$ & 14.52 & 0.29 & 0.060 \\
\hline$\pi(\mathrm{C} 34-\mathrm{C} 35)$ & $\pi^{*}(\mathrm{C} 31-\mathrm{C} 36)$ & 17.47 & 0.26 & 0.061 \\
\hline$\pi(\mathrm{C} 34-\mathrm{C} 35)$ & $\pi^{*}(\mathrm{C} 32-\mathrm{C} 33)$ & 21.89 & 0.28 & 0.072 \\
\hline$\pi(\mathrm{C} 34-\mathrm{C} 35)$ & $\Pi^{*}(\mathrm{~N} 39-\mathrm{N} 40)$ & 23.77 & 0.23 & 0.069 \\
\hline$\pi(N 39-N 40)$ & $\pi^{*}(\mathrm{C} 34-\mathrm{C} 35)$ & 10.41 & 0.39 & 0.062 \\
\hline$\pi(N 39-N 40)$ & $\pi^{*}(\mathrm{C} 41-\mathrm{C} 42)$ & 11.38 & 0.39 & 0.064 \\
\hline$\pi(C 41-C 42)$ & $\pi^{*}(\mathrm{~N} 39-\mathrm{N} 40)$ & 19.44 & 0.23 & 0.062 \\
\hline$\pi(\mathrm{C} 41-\mathrm{C} 42)$ & $\pi^{*}(\mathrm{C} 43-\mathrm{C} 44)$ & 22.43 & 0.27 & 0.070 \\
\hline$\pi(\mathrm{C} 41-\mathrm{C} 42)$ & $\pi^{*}(\mathrm{C} 45-\mathrm{C} 46)$ & 18.05 & 0.29 & 0.066 \\
\hline$\pi(\mathrm{C} 43-\mathrm{C} 44)$ & $\pi^{*}(\mathrm{C} 41-\mathrm{C} 42)$ & 18.48 & 0.29 & 0.066 \\
\hline$\pi(\mathrm{C} 43-\mathrm{C} 44)$ & $\Pi^{*}(\mathrm{C} 45-\mathrm{C} 46)$ & 19.12 & 0.29 & 0.068 \\
\hline$\pi(C 45-C 46)$ & $\pi^{*}(\mathrm{C} 41-\mathrm{C} 42)$ & 20.04 & 0.28 & 0.068 \\
\hline$\pi(\mathrm{C} 45-\mathrm{C} 46)$ & $\pi^{*}(\mathrm{C} 43-\mathrm{C} 44)$ & 19.19 & 0.27 & 0.065 \\
\hline n1 (N30) & $\pi^{*}(\mathrm{C} 31-\mathrm{C} 36)$ & 46.27 & 0.27 & 0.104 \\
\hline n2 (O48) & $\sigma^{*}(\mathrm{~S} 47-049)$ & 16.32 & 0.52 & 0.082 \\
\hline n2 (O48) & $\sigma^{*}(\mathrm{~S} 47-050)$ & 19.98 & 0.50 & 0.089 \\
\hline n3 (O48) & $\sigma^{*}(\mathrm{C} 44-\mathrm{S} 47)$ & 19.55 & 0.44 & 0.083 \\
\hline n2 (O49) & $\sigma^{*}(\mathrm{~S} 47-\mathrm{O} 48)$ & 14.11 & 0.59 & 0.082 \\
\hline n2 (O49) & $\sigma^{*}(\mathrm{~S} 47-050)$ & 14.20 & 0.52 & 0.078 \\
\hline n3 (O49) & $\sigma^{*}(\mathrm{C} 44-\mathrm{S} 47)$ & 15.35 & 0.47 & 0.077 \\
\hline $\mathrm{n} 2(\mathrm{O} 50)$ & $\sigma^{*}(\mathrm{~S} 47-048)$ & 16.40 & 0.59 & 0.089 \\
\hline n3 (O50) & $\sigma^{*}(\mathrm{C} 44-\mathrm{S} 47)$ & 10.43 & 0.51 & 0.065 \\
\hline
\end{tabular}

accounts for the lengthening of the $\mathrm{O} 11-\mathrm{H} 23$ bond upon the ion pair formation (Table 5).

\section{CONCLUSION}

The proposed methods make use of simple reagent, which a basic analytical laboratory can afford. The reagents utilized in the proposed methods are low cost, readily available and the proposed methods do not involve critical reaction conditions or tedious sample preparation. The methods are unaffected by slight variations in experimental conditions, such as $\mathrm{pH}$, reagent concentration or temperature.

The proposed methods are sufficiently sensitive to permit determination even down to $0.1 \mu \mathrm{g} \mathrm{mL}$. The sensitivity in terms of molar absorptivity and the precision in terms of RSD of the methods are very suitable for the determination of ET in tablets and biological fluids. Moreover, the methods are free from interference by common additives and excipients. The ET-MO ion pair found to have larger interaction energy (higher stability) than the ET-BCG ion pair as inferred from their interaction energies.

\section{DECLARATIONS}

\section{Acknowledgement}

None.

\section{Conflict of Interest}

No conflict of interest associated with this work.

\section{Contribution of Authors}

The authors declare that this work was done by the authors named in this article and all liabilities pertaining to claims relating to the content of this article will be borne by them.

\section{Open Access}

This is an Open Access article that uses a funding model which does not charge readers or their institutions for access and distributed under the 
terms of the Creative Commons Attribution License (http://creativecommons.org/licenses/by/ 4.0) and the Budapest Open Access Initiative (http://www.budapestopenaccessinitiative.org/rea d), which permit unrestricted use, distribution, and reproduction in any medium, provided the original work is properly credited.

\section{REFERENCES}

1. Miller E, Wiener L, Bloomfield D. Etilefrine in the Treatment of Levodopa-Induced Orthostatic Hypotension. Arch Neurol 1973; 29: 99-103.

2. Hengstmann JH, Weyand $U$, Dengler JH. The physiological disposition of etilefrine in man. Eur J Clin Pharmacol 1975; 9: 179-187.

3. Raviele $A$, Brignole $M$, Sutton $R$, Alboni $P$, Giani $P$, Menozzi C, Moya A. Effect of etilefrine in preventing syncopal recurrence in patients with vasovagal syncope: a double-blind, randomized, placebo-controlled trial. Circulation 1999; 99: 1453-1457.

4. Okpala I, Westerdale N, JegedeT, Cheung B. Etilefrine for the prevention of priapism in adult sickle cell disease. Br J Haematol 2002; 118: 918-921.

5. Bakry RS, El-Walily AFM, Belal SF. Spectrophotometric determination of etilefrine hydrochloride, prenalterol hydrochloride and ritodrine hydrochloride in pharmaceutical dosage form through nitrosation and subsequent copper chelation. Anal Lett 1996; 29: 409422.

6. Aly FA, Tamimi SA, Alwarthan AA. Determination of phenolic sympathomimetic drugs in pharmaceutical samples and biological fluids by flow injection chemiluminescence. J AOAC Int 2000; 83: 1299-1305.

7. Shoukry AF, Issa YM, Rizk MS, El-Nashar RM. Etilefrine plastic membrane electrodes based on individual and mixed ion-exchangers of etilefrinium phosphotungstate and tetraphenylborate. Anal Lett 1996; 29: 1463-1475.

8. Shukrallah IZF, Sakla AB. Development of an analytical protonmagnetic resonance (PMR) spectroscopic method for the determination of etilefrine in bulk and pharmaceutical forms. Spectrosc Lett 1989; 22: 101108.

9. Hengstmann JH, Hengstmann R, Schwonzen S, Dengler HJ. Dihydroergotamine increases the bioavailability of orally administered etilefrine. Eur J Clin Pharmacol 1982; 22: 463-470.

10. Statheropoulos $M$, Smaragadis E, Tzamtzis $N$, Georgakopoulos C. Principal component analysis for resolving coeluting substances in gas chromatographymass spectrophotometry doping control analysis. Anal Chim Acta 1996; 331: 53-61.

11. Rominger KL, Hitzenberger G. Pharmacokinetic comparison of etilefrine to its prodrug, the stearic acid ester of etilefrine. Int J Clin Ther Toxicol 1980; 18: 150157.

12. Kauert G, Herrle I, Schoppe kB. Detection of oxilofrine in plasma and urine by high-performance liquid chromatography with electrochemical detection and comparison with gas chromatography-mass spectrometry. J Chromatogr 1988; 15: 291-300.

13. Kojima K, Yamanaka M, Nakanishi Y, Arakawa S. High performance liquid chromatographic determination of etilefrine in human plasma using combined solid-phase and organic-solvent extraction and electrochemical detection. J Chromatogr Biomed Appl 1990; 525: 210 213.

14. Kolle P, Dronskowski R. Hydrogen Bonding in the Crystal Structures of the lonic Liquid Compounds Butyl dimethyl imidazolium Hydrogen Sulfate, Chloride, and Chloroferrate (II, III). Inorg Chem 2004; 43: 2803-2809.

15. Wulf A, Fumino K, Ludwig R. Spectroscopic Evidence for an Enhanced Anion-Cation Interaction from Hydrogen Bonding in Pure Imidazolium lonic Liquids. Angew Chem Int Ed. 2010; 49: 449-453.

16. Remsing RC, Wildin JL, Rapp AL, Moyna G. Hydrogen Bonds in lonic Liquids Revisited: 35/37CI NMR Studies of Deuterium Isotope Effects in 1-n-Butyl-3Methylimidazolium Chloride. J Phys Chem B 2007; 111: 11619-11622.

17. Dong K, Zhang SJ, Wang DX, Yao XQ. Hydrogen Bonds in Imidazolium Ionic Liquids. J Phys Chem A 2006; 110 : 9775-9782.

18. Fumino $K$, Wulf $A$, Ludwig $R$. The Cation-Anion Interaction in Ionic Liquids Probed by Far-Infrared Spectroscopy. Angew Chem Int Ed. 2008; 47: 38303834.

19. Frisch MJ, Trucks GW, Schlegel HB, Scuseria GE, Robb $M A$, Cheeseman JR, Montgomery JA, Vreven $T(J r)$, Kudin K, Burant JCN. Gaussian 03, Revision E.01, Gaussian, Inc: Pittsburgh, PA, 2003.

20. Saber AL, El-Sayed GO. Extractive Spectrophotometric Determination of Anti-inflammatory Drug Nimesulide in Pharmaceutical Formulations and Human Plasma. J Food Drug Anal 2011; 19: 1-6.

21. Amin AS, El-Mossalamy MA, Killa HM, Saber AL. Three Spectrophotometric Methods for the Determination of Oxomemazine Hydrochloride in Bulk and Pharmaceutical Formulations Using Bromocresol Green, Congo Red, and Methyl Orange. J Anal Lett 2008; 41; 80-89.

22. Miller JC, Miller JN. Statistics in Analytical Chemistry, 3rd edn. Chichester: Ellis Horwood 1993.

23. European Pharmacopoeia. 5.0. 01/2005, 1205; 2005.

24. Bondi A. van der Waals Volumes and Radii. J Phys Chem 1964; 68: 441-451.

25. Anantharaj R, Banerjee T. Quantum chemical studies on the simultaneous interaction of thiophene and pyridine with ionic liquid. AIChE J. 2011; 749-764.

26. Lü R, Qu Z, Lin J. Comparative study of interactions between thiophenelpyridinelbenzenelheptane and 1 butyl-3-methylimidazolium trifluoro methane sulfonate by density functional theory. J Mol Liq 2013; 180:207-214.

27. Tsuneda T, Song JW, Suzuki S, Hirao K. On Koopmans's theorem in density functional theory. J Chem Phys 2010; 133: 174101-174109.

Trop J Pharm Res, October 2017; 16(10): 2499 
28. Mou ZX, Li P, Bu YX, Wang WH, Shi JY, Song $R$. Investigations of coupling characters in ionic liquids formed between the 1-ethyl-3 methyl imidazolium cation and the glycine anion. J Phys Chem B 2008; 112: 50885097.

29. Murray JS, Politzer P. Statistical analysis of the molecular surface electrostatic potential: an approach to describing noncovalent interactions in condensed phases. $J \mathrm{Mol}$ Struct (Theochem) 1998; 425: 107-112.
30. Politzer P, Murray JS, Peralta-Inga Z. Molecular surface electrostatic potentials in relation to noncovalent interactions in biological systems. Int J Quantum Chem 2001; 85: 676-684.

31. Weinhold F, Landis C. Valency and Bonding: A Natural Bond Orbital Donor-Acceptor Perspective, Cambridge: Cambridge University Press; 2005. 